\title{
ARTICLE
}

Received 9 Mar 2016 | Accepted 26 Sep 2016 | Published 9 Nov $2016 \quad$ DOl: 10.1038/ncomms13343 OPEN

\section{BMI1 regulates PRC1 architecture and activity through homo- and hetero-oligomerization}

Felicia Gray ${ }^{1, \star}$, Hyo Je Cho ${ }^{1, \star}$, Shirish Shukla ${ }^{1, \star}$, Shihan He${ }^{1}$, Ashley Harris ${ }^{2,3}$, Bohdan Boytsov ${ }^{1}$, Łukasz Jaremko ${ }^{4,5}$, Mariusz Jaremko ${ }^{5}$, Borries Demeler ${ }^{6}$, Elizabeth R. Lawlor ${ }^{1,2,3}$, Jolanta Grembecka ${ }^{1} \&$ Tomasz Cierpicki $^{1}$

BMI1 is a core component of the polycomb repressive complex 1 (PRC1) and emerging data support a role of BMI1 in cancer. The central domain of BMI1 is involved in protein-protein interactions and is essential for its oncogenic activity. Here, we present the structure of BMI1 bound to the polyhomeotic protein PHC2 illustrating that the central domain of BMI1 adopts an ubiquitin-like (UBL) fold and binds PHC2 in a $\beta$-hairpin conformation. Unexpectedly, we find that the UBL domain is involved in homo-oligomerization of BMI1. We demonstrate that both the interaction of BMI1 with polyhomeotic proteins and homo-oligomerization via UBL domain are necessary for $\mathrm{H} 2 \mathrm{~A}$ ubiquitination activity of PRC1 and for clonogenic potential of U2OS cells. Here, we also emphasize need for joint application of NMR spectroscopy and $\mathrm{X}$-ray crystallography to determine the overall structure of the BMI1-PHC2 complex.

\footnotetext{
${ }^{1}$ Department of Pathology, University of Michigan, Ann Arbor, Michigan 48109, USA. ${ }^{2}$ Translational Oncology Program, University of Michigan, Ann Arbor, Michigan 48109, USA. ${ }^{3}$ Department of Pediatrics and Communicable Diseases, University of Michigan, Ann Arbor, Michigan 48109, USA. ${ }^{4}$ Deutsches Zentrum fur Neurodegenerative Erkrankungen (DZNE), Am Fassberg 11, 37077 Goettingen, Germany. ${ }^{5}$ Max-Planck Institute of Biophysical Chemistry, NMRbased Department for Structural Biology, Am Fassberg 11, 37077 Goettingen, Germany. ${ }^{6}$ Department of Biochemistry, The University of Texas Health Science Center at San Antonio, San Antonio, Texas 78229, USA. * These authors contributed equally to this work. Correspondence and requests for materials should be addressed to T.C. (email: tomaszc@umich.edu).
} 
B MI1 (B cell-specific Moloney murine leukemia virus integration site 1) is a polycomb group family member and emerging data support an important role for BMI1 in cancer. The gene encoding BMI1 was initially identified as an oncogene inducing $\mathrm{B}$ - and T-cell leukemias ${ }^{1}$. Further studies found that BMII is a stem cell gene that determines the proliferative capacity and self-renewal of normal and leukemic stem cells ${ }^{2}$. BMI1 is frequently overexpressed in patients with hematologic ${ }^{3-5}$ and solid cancers $^{6-8}$. Silencing of $B M I 1$ impairs cancer cell proliferation and tumour growth in cancer models ${ }^{9-15}$, suggesting that BMI1 might represent a valid target for therapeutic intervention $^{16,17}$.

The mammalian polycomb repressive complex 1 (PRC1) is a multisubunit protein complex involved in gene silencing ${ }^{18,19}$. The canonical PRC1 complex is composed of four core subunits: CBX (polycomb; CBX2/4/6/7/8), PCGF (polycomb group factors; PCGF1-6), PHC (polyhomeotic homologues; $\mathrm{PHC1} / 2 / 3)$ and RING E3 ligase $(\mathrm{RING} 1 \mathrm{~A} / \mathrm{B})^{18,19}$. The presence of numerous orthologs results in diverse compositions of PRC1 with potentially different functions ${ }^{19-21}$. PRC1 has at least two distinct activities contributing to repressed gene transcription: mono-ubiquitination of histone H2A on Lys119 (refs 22,23) and chromatin compaction ${ }^{24,25}$. The BMI1 protein, also known as PCGF4 (polycomb group RING finger protein 4), is a central component of the canonical PRC1 complex and has a dual role in PRC1 activity: regulation of $\mathrm{H} 2 \mathrm{~A}$ ubiquitination activity $26-28$ and mediation of protein-protein interactions ${ }^{29-33}$.

$\mathrm{BMI} 1$ is a $37 \mathrm{kDa}$ protein composed of three distinct regions: a N-terminal RING domain 26,27 , a central domain ${ }^{34}$ and a C-terminal proline-serine rich domain involved in the regulation of protein stability ${ }^{35}$. The RING domain of BMI1 forms a complex with RING1A/B proteins, which constitutes the heterodimeric E3 ubiquitin ligase subunit of the PRC1 complex $^{26,27}$. BMI1 itself has no ubiquitin ligase activity but through a direct interaction it stabilizes RING1A/B, leading to increased H2A ubiquitination activity ${ }^{26,28}$. The central domain of BMI1 was initially predicted as a putative helix-turn-helix (HTH) domain ${ }^{36}$ and more recently was defined as an ubiquitin-like (UBL) domain, also called RAWUL (RING finger- and WD40-associated ubiquitin-like) domain ${ }^{34}$. This domain is involved in protein-protein interactions and its best characterized binding partners are the polyhomeotic proteins (PHC1, PHC2, PHC3 $)^{29,30}$. In addition to interactions within PRC1, the BMI1 central domain has also been implicated in other protein-protein interactions, including the transcription factors E4F1 (ref. 31), Zfp277 (ref. 32) and the PLZF-RARA fusion protein $^{33}$.

Functional studies revealed that the central domain of BMI1 is essential for its oncogenic activity. Deletion analysis shows that this domain is necessary for transcriptional repression activity $^{36}$, immortalization of mammary epithelial cells ${ }^{37}$ and lifespan extension of human fibroblasts ${ }^{38}$. However, the structure and molecular mechanisms determining how the central domain of BMI1 contributes to the overall architecture and function of the canonical PRC1 complex have not been fully elucidated. To address these questions we determined the three-dimensional structure of the PHC2-BMI1 complex revealing that the BMI1 central domain adopts an ubiquitin-like (UBL) fold and binds a short, 24 amino acid fragment of PHC2 in a $\beta$-hairpin conformation. Unexpectedly, we find that the UBL domain is involved in homo-oligomerization of BMI1. Our work reveals that both hetero- and homooligomerization of the UBL domain contribute to BMI1 function and activity.

\section{Results}

The BMI1 central domain binds directly to the PHC2 HD1. The central domain of BMI1 has been reported to interact with the polyhomeotic PHC2 protein and we sought to characterize the molecular details of this interaction (Fig. 1a) $)^{29,30}$. To confirm a direct interaction between BMI1 and PHC2 we developed a cellular pulldown assay overexpressing an Avi-tagged BMI1 construct lacking the N-terminal RING domain (Avi-BMI1 $\left.1_{106-326}\right)$ and a Myc-tagged full-length short isoform of PHC2 (PHC2_B). Streptavidin pulldown of biotinylated Avi-BMI1 $1_{106-326}$ demonstrates that the fragment of BMI1 lacking the RING domain interacts with Myc-PHC2 (Fig. 1b). Further co-immunoprecipitation experiments confirmed the interaction of full length BMI1 with PHC2 (Supplementary Fig. 1a) and showed slightly less efficient binding with full length BMI1 when compared to BMI1 ${ }_{106-326}$ (Supplementary Fig. 1b). To define the central domain within BMI1 that binds PHC2 and is suitable for structural studies we employed bioinformatic analysis and selected a construct encompassing BMI1 residues 106-240. While the ${ }^{1} \mathrm{H}-{ }^{15} \mathrm{~N}$ HSQC spectrum for this construct is consistent with a folded domain, it is not optimal for structural studies due to the presence of a significant number of disordered residues (Fig. 1c, top). To define the boundaries of the globular central domain we employed carbon detected NMR experiments to efficiently identify flexible regions. We assigned disordered fragments in $\mathrm{BMI}_{106-240}$ by employing a combination of ${ }^{13} \mathrm{C}$-detected 2D CACO, CBCACO and CANCO experiments using a previously published protocol ${ }^{39}$. We identified residues 106-120 and 236-240 as being highly flexible in solution (Supplementary Fig. 2). Deletion of these residues significantly improved the quality of ${ }^{1} \mathrm{H}-{ }^{15} \mathrm{~N}$ HSQC spectra yielding a central domain construct $\mathrm{BMI}_{121-235}$ suitable for structural studies (Fig. 1c, bottom).

Previous studies found that in cells the homology domain 1 (HD1) of PHC2 mediates the interaction with BMI1 (refs 30,40). To validate the interaction of PHC2 HD1 (residues 1-79) with the central domain of BMI1 and assess the binding affinity we employed isothermal titration calorimetry (ITC). We found that $\mathrm{PHC}_{1-79}$ binds to BMI1 $1_{121-235}$ with sub-micromolar affinity $\left(K_{\mathrm{D}}=398 \mathrm{nM}\right)$ and 1:1 stoichiometry (Fig. 1d). These results validate a direct interaction between the HD1 domain of PHC2 and the central domain of BMI1.

BMI1 recognizes a short fragment of PHC2. To map PHC2 residues involved in binding to BMI1 we employed NMR. We found that $\mathrm{PHC}_{1-79}$ is disordered in solution as judged by poor peak dispersion on the ${ }^{1} \mathrm{H}-{ }^{15} \mathrm{~N}$ HSQC spectra (Supplementary Fig. 3). To identify the minimal motif of PHC2 required for binding to BMI1, we again employed the carbon-detected NMR experiments. We titrated ${ }^{13} \mathrm{C},{ }^{15} \mathrm{~N} \quad \mathrm{PHC}_{1-79}$ with unlabelled BMI1 and found strong broadening for a subset of resonances on 2D CACO and CBCACO spectra (Fig. 1e). This indicated that a shorter fragment of $\mathrm{PHC}_{1-79}$ is involved in binding to BMI1, and to identify these residues we assigned backbone chemical shifts in $\mathrm{PHC}_{1-79}$ using $\mathrm{CACO}, \mathrm{CBCACO}$ and $\mathrm{CANCO}$ experiments. We found that the most significantly perturbed signals correspond to $\mathrm{PHC} 2$ residues 33-59 indicating that this represents the BMI1-binding motif in the PHC2 (Fig. 1f). To validate this finding we tested the binding of PHC2 fragments using ITC and found that $\mathrm{PHC}_{33-56}$ binds to BMI1 with a similar affinity as $\mathrm{PHC}_{1-79}\left(K_{\mathrm{D}}=413 \mathrm{nM}\right)$ (Supplementary Fig. 4). Furthermore, deletion of residues 30-51 from full length PHC2 abolished the interaction with $\mathrm{BMI}_{106-326}$ and full length BMI1 in pull-down experiments performed in HEK293 cells (Fig. 1a, Supplementary Fig. 1a), further supporting that this 
a

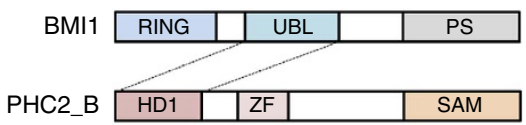

b

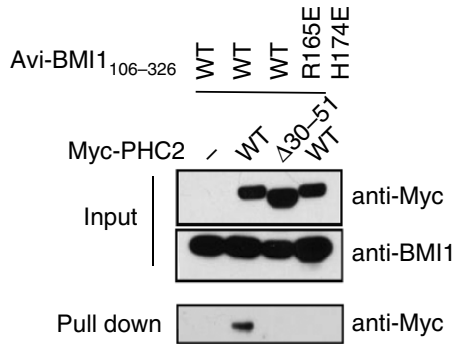

c

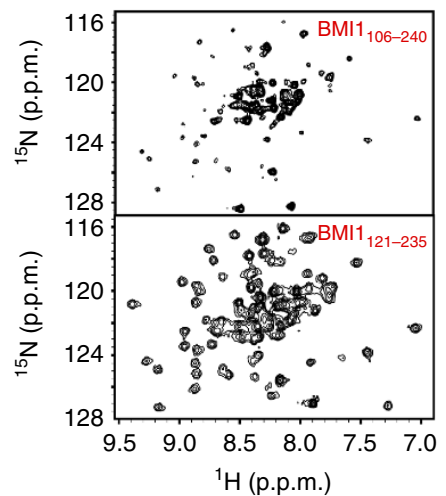

d



f

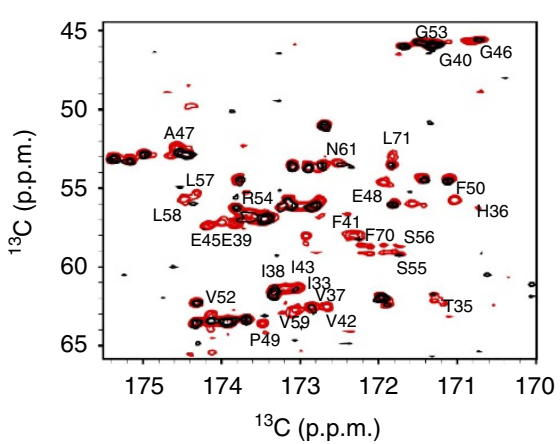

43

53

PHC2_B 19 GENKPPQAIVKPQI_LTHVIEGFVI_QEGAEPFPVGRSSLLVGNLKKKYA---QGFL 71

PHC1 720 GDSKPPQAIVKPQILTHIIEGFVIQEGAEPFPVGCSQLLKESEKP-LQ---TG-L 769

PHC3 688 IENKPPQAIVKPQILTHVIEGFVIQEGLEPFPVSRSSLLIEQPVKKRPLLDNQVI 742

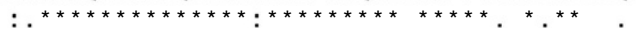

Figure 1 | Mapping of the BMI1-PHC2 interaction. (a) Schematics of the domain structures of BMI1 and PHC2. Dashed lines connect the interacting UBL and HD1 domains. (b) Streptavidin pull-down in HEK293 cells transfected with Avi-tagged wild-type BMI1 fragment 106-326 or R165E, H174E double mutant, BirA and Myc-tagged wild-type PHC2_B or PHC2_B with deleted residues 30-51. Western blots are probed as indicated. (c) Optimization of BMI1 constructs for structural studies: (top) ${ }^{1} \mathrm{H}_{-}{ }^{15} \mathrm{~N} \mathrm{HSQC}$ spectrum of $\mathrm{BMI1}_{106-240}$; (bottom) ${ }^{1} \mathrm{H}_{-}{ }^{15} \mathrm{~N} \mathrm{HSQC}$ spectrum of BMI1 $121-235$. (d) $\mathrm{Characterization}$ of the affinity and stoichiometry of the BMI1-PHC2 $2_{1-79}$ interaction using isothermal titration calorimetry with BMI1 $121-235$ titrated with $\mathrm{PHC} 2_{1-79}$. (e) Superposition of CACO spectra for $60 \mu \mathrm{M} \mathrm{PHC2} 2_{1-79}$ (red) and $60 \mu \mathrm{M} \mathrm{PHC2} 2_{1-79}$ with equimolar concentration of unlabelled BMI1 $121-235$ (black). PHC2 residues broadened in the presence of BMI1 are labelled. (f) Sequence alignment of the three human PHC proteins. Residues of PHC2_B that are perturbed on addition of $\mathrm{BMI}_{121-235}$ are shown in red.

region is important for binding. Overall, we concluded that a relatively short, 24 amino acid fragment of PHC2 ( $\left.\mathrm{PHC}_{33-56}\right)$ represents the BMI1 binding motif. This motif is strongly conserved between PHC2, PHC1 and PHC3 suggesting that BMI1 interacts with the three members of the polyhomeotic family (Fig. 1f) in a very similar manner and with similar affinities.

Structure determination using joint $\mathrm{X}$-ray and NMR refinement. To understand the molecular basis of the BMI1-PHC2 interaction we pursued structural studies. We obtained crystals of $\mathrm{BMI} 1_{121-235}$ co-crystalized in the presence of the $\mathrm{PHC} 2_{33-56}$ fragment, which diffracted to $2.5 \AA$ resolution (Table 1 ). To determine the crystal structure we used molecular replacement using a structural model derived from the BMI1 homolog PCGF1, with $31 \%$ sequence identity to BMI1 (ref. 41) (Table 1). The structure confirmed that the central domain of BMI1 adopts an ubiquitin-like (UBL) fold (Fig. 2a). While we could refine the structure of the UBL domain we were not able to model the PHC2 fragment into the remaining electron density.
The unmodelled electron density was found in a wide opening between the $\beta 2$ strand and $\alpha 1$ helix at the interface between the two BMI1 UBL symmetry related molecules (Fig. 2a, Supplementary Fig. 5). The incomplete model of the complex is reflected by relatively high $\mathrm{R}$-factor values (Table 1 ).

To determine the complete structure of the BMI1-PHC2 complex we turned to solution NMR. Due to limited solubility and stability of the BMI1-PHC2 complex we made a fusion protein connecting $\mathrm{PHC}_{30-64}$ fragment fused to the $\mathrm{N}$-terminus of the BMI1 UBL domain. This construct was designed to include the intact BMI1 interacting motif in PHC2 as well as a short, 8 amino acid linker to ensure proper folding of the complex. The HSQC spectrum of the fusion protein was nearly identical to the spectrum of ${ }^{15} \mathrm{~N}$ BMI1 UBL saturated with unlabelled $\mathrm{PHC2}_{32-61}$, demonstrating that the fusion protein recapitulates the structure of the non-covalent complex (Supplementary Fig. 6). We noted significant broadening of PHC2-BMI1 resonances at concentrations above $200 \mu \mathrm{M}$, which precluded complete chemical shift assignment and determination of the PHC2-BMI1 structure solely based on the NMR data. However, we obtained nearly complete backbone and methyl group 


\begin{tabular}{|c|c|}
\hline PDB ID & 5FR6 \\
\hline \multicolumn{2}{|l|}{ Data collection } \\
\hline Space group & $\mathrm{P} 3_{2} 12$ \\
\hline \multicolumn{2}{|l|}{ Cell dimensions } \\
\hline$a, b, c(\AA)$ & $78.28,78.28,43.12$ \\
\hline$\alpha, \beta, \gamma\left({ }^{\circ}\right)$ & $90.00,90.00,120.00$ \\
\hline Resolution $(\AA)$ & $39.41-2.50(2.54-2.50)^{\star}$ \\
\hline$R_{\text {sym }}$ & $8.7(47.7)$ \\
\hline$|/ \sigma|$ & $33.93(3.28)$ \\
\hline Completeness (\%) & $99.8(99.6)$ \\
\hline Redundancy & $10.0(8.3)$ \\
\hline \multicolumn{2}{|l|}{ Refinement } \\
\hline Resolutions ( $\AA$ ) & $39.14-2.51$ \\
\hline No. reflections & 52,849 \\
\hline$R_{\text {work }} / R_{\text {free }}$ & $23.71 / 32.08$ \\
\hline \multicolumn{2}{|l|}{ No. atoms } \\
\hline Protein & 692 \\
\hline Ligand/ion & - \\
\hline Water & 32 \\
\hline \multicolumn{2}{|l|}{ B-factors } \\
\hline Protein & 57.471 \\
\hline Ligand/ion & - \\
\hline Water & 62.509 \\
\hline \multicolumn{2}{|l|}{ R.m.s. deviation } \\
\hline Bond length $(\AA)$ & 0.013 \\
\hline Bond angle $\left({ }^{\circ}\right)$ & 1.783 \\
\hline
\end{tabular}

BMI1, B cell-specific Moloney murine leukemia virus integration site 1; UBL, ubiquitin like. *Values in parentheses are for highest-resolution shell.

assignment for PHC2-BMI1 and assigned a significant number of intra-PHC2 and PHC2-BMI1 NOEs. To determine the structure of the PHC2-BMI1 complex we integrated the crystal structure of the UBL domain and NMR restraints for intramolecular PHC2 and intermolecular PHC2-BMI1 contacts. The initial structure of PHC2-BMI1 was calculated in CYANA ${ }^{42}$ followed by refinement using the Rosetta software incorporating both X-ray crystallography and NMR data ${ }^{43,44}$. The structure of the UBL domain was constrained during the refinement with the exception of side chains of residues $160-178$ at the interface with PHC2 (Table 2). Joint refinement using the crystal structure of the BMI1 UBL domain and NMR distance restraints for PHC2 was necessary to determine the overall structure of the PHC2-BMI1 complex (Fig. 2b).

The UBL domain binds PHC2 motif in $\beta$-hairpin conformation. The structure of the PHC2-BMI1 complex shows that PHC2 binds into a hydrophobic site between the $\alpha 1$ helix and $\beta 2$ strand (Fig. 2c). PHC2 residues 33-47 are well structured and adopt a $\beta$-hairpin conformation in the complex (Fig. 2c). The PHC2-BMI1 interaction involves an antiparallel $\beta$-sheet formed between the $\beta$-hairpin of PHC2 and the $\beta 2$ strand of BMI1 UBL, which is stabilized by the hydrogen bonds between BMI1 Tyr163 and PHC2 Gly46. The PHC2 $\beta$-hairpin buries the hydrophobic side chains of Ile38, Phe41 and Ile43 which pack onto the hydrophobic BMI1 interface lined with residues Leu164, Cys166, Pro167, Met170, Leu175 and Phe178 (Fig. 2d). Notably, PHC2 Glu45 is buried at the interface and makes electrostatic contacts with BMI1 Arg162 and Lys182 (Fig. 2d). Mapping of PHC2 by ${ }^{13} \mathrm{C}$ detected NMR experiments revealed that a longer fragment $\left(\mathrm{PHC}_{33-56}\right)$ is involved in binding to BMI1. Based on the structure of PHC2-BMI1 we determined that PHC2 residues 48-56 are not well ordered in the structure, as supported by the random coil chemical shifts and lack of long range NOEs. It is likely that these residues are involved in long range electrostatic interactions stabilizing the PHC2-BMI1 complex (for example, the interaction of PHC2 Glu48 with BMI1 Arg165).

Superposition of the PHC2-BMI1 structure with the crystal structure of BMI1 UBL shows that the PHC2 fragment overlaps with the unmodelled electron density observed in the crystal (Supplementary Fig. 7). Since PHC2 binds at the interface of two symmetry related BMI1 UBL molecules, most likely in the crystal structure one molecule of $\mathrm{PHC} 2$ is bound to each monomer with $50 \%$ occupancy. This unusual binding stoichiometry observed in the crystal structure precludes modelling of the complex solely based on the X-ray data.

Point mutations in BMI1 disrupt the interaction with PHC2. We used the structure of the PHC2-BMI1 complex to design mutations in BMI1 disrupting the interaction with $\mathrm{PHC} 2$. We rationalized that mutation of Arg165 and His174 in BMI1 to glutamic acids would introduce a significant electrostatic repulsion with PHC2 Glu48 and Glu39, respectively. We tested binding of these mutants to fluorescein-tagged $\mathrm{PHC} 2_{32-61}$ using a fluorescence polarization assay (Fig. 2e). While wild-type BMI1 UBL binds $\mathrm{PHC}_{32-61}$ with $K_{\mathrm{D}}=0.215 \pm 0.016 \mu \mathrm{M}$, both BMI1 mutants showed substantially reduced binding affinities. The R165E mutation reduced the binding affinity by $\sim 30$-fold $\left(K_{\mathrm{D}}=5.9 \pm 0.9 \mu \mathrm{M}\right)$ and the $\mathrm{H} 174 \mathrm{E}$ mutation resulted in a 100 -fold loss in the binding affinity $\left(K_{\mathrm{D}}=20.13 \pm 2.8 \mu \mathrm{M}\right)$. Introduction of the double R165E/H174E mutation into BMI1 nearly completely abolished the interaction with PHC2 $\left(K_{\mathrm{D}}>50 \mu \mathrm{M}\right)$. NMR analysis of the BMI1 UBL domain mutants revealed that these mutants remain folded in solution (Supplementary Fig. 8a) and confirmed that the R165E/H174E double mutant had significantly reduced binding to PHC2 (Supplementary Fig. 8b). To further validate that point mutations in BMI1 impair binding to PHC2 we performed pull-down experiments in HEK293 cells and found that the BMI1 R165E/H174E mutant does not associate with PHC2 (Fig. 1b, Supplementary Fig. 1). To further probe whether hydrophobic contacts contribute to the BMI1-PHC2 interaction we introduced M170E point mutation in BMI1 and found that it significantly reduced the binding to PHC2 by $\sim 80$-fold $\left(K_{\mathrm{D}}=17 \pm 1.7 \mu \mathrm{M}\right)$ (Supplementary Fig. 8c).

BMI1 UBL forms higher order oligomers in solution. We observed that the NMR spectra of all tested BMI1 constructs showed a concentration-dependent peak broadening consistent with protein self-association in solution. Importantly, the self-association of BMI1 was not affected by the presence of PHC2 suggesting that oligomerization may represent an intrinsic property of the BMI1 UBL domain. To characterize the oligomerization of the BMI1 UBL domain we employed analytical ultracentrifugation experiments ${ }^{45}$. We found a concentration dependent increase in sedimentation coefficients for the BMI1 UBL-PHC2 ${ }_{1-79}$ complex (Fig. 3a). Although we were not able to determine quantitatively the population of oligomers, these data are consistent with the propensity of the BMI1-PHC2 complex to form higher order oligomers in solution.

To investigate potential oligomerization interfaces we inspected the crystal packing of the UBL domain in the structure of the BMI1-PHC2 complex. Analysis of the crystal packing using PISA software ${ }^{46}$ suggests two possible homo-oligomerization interfaces (Fig. 3b). The first interface is predominantly hydrophobic and comprises residues D184-F189 and Y225-T230 and has a buried surface area of $462 \AA^{2}$ with predicted $\Delta G=-10.4 \mathrm{kcal} \mathrm{mol}^{-1}$ for the association energy. The second interface is centered 
a

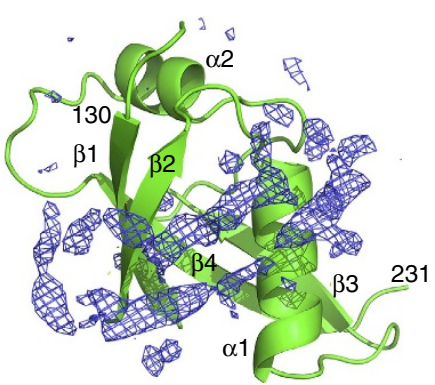

c

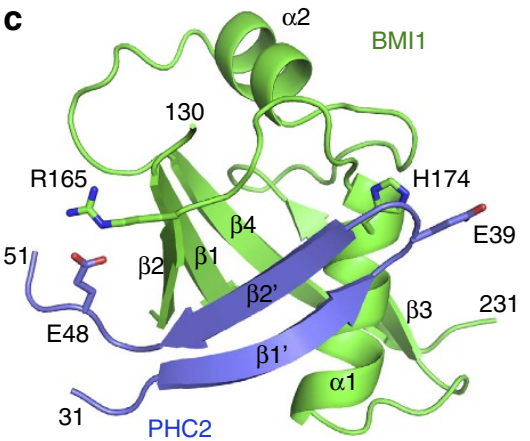

e

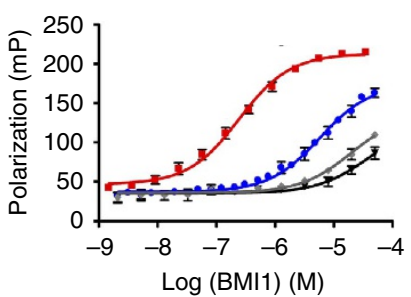

b

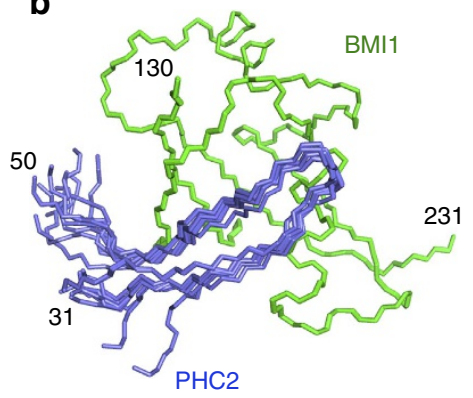

d



BMl1 WT $\quad K_{D}=0.215 \pm 0.016 \mu \mathrm{M}$

R165E $\quad K_{\mathrm{D}}=5.96 \pm 0.9 \mu \mathrm{M}$

H174E $\quad K_{D}=20.13 \pm 2.8 \mu \mathrm{M}$

R165E/H174E $K_{\mathrm{D}}>50 \mu \mathrm{M}$

Figure 2 | Structure of the PHC2-BMI1 complex. (a) Crystal structure of the BMI1 UBL domain with Fo-Fc electron density map showing unmodelled density (blue). (b) Ten lowest energy structures of the PHC2-BMI1 complex determined using joint refinement employing NMR and X-ray data. The backbone of BMI1 residues 130-231 is shown in green and PHC2 residues 31-50 are shown in blue. Unstructured residues are omitted for clarity. (c) The overall structure of the PHC2-BMI1 complex using ribbon representation. Side chains of residues mutated to disrupt the PHC2-BMI1 interaction are shown in sticks. (d) Details of the PHC2-BMI1 interface. (e) Binding affinities of PHC2 with BMI1 variants determined using fluorescence polarization (FP) experiments titrating FITC-PHC2 $2_{32-61}$ with wild-type BMI1 UBL or point mutants. Experiments were performed in duplicates, error bars represent s.d.; $K_{\mathrm{D}}$ is reported as an average and s.d. from three independent experiments.

around Ile212 and involves a cluster of tyrosine side chains (Tyr202, Tyr203, Tyr211 and Tyr213) that form a hydrogen bond network with backbone carbonyls. This interface is smaller, with $398 \AA^{2}$ buried surface area and with a predicted $\Delta \mathrm{G}=-2.4 \mathrm{kcal} \mathrm{mol}^{-1}$ for the association energy. To probe these two potential oligomerization interfaces we designed two point mutations: F189Q and I212E with the goal to disrupt hydrophobic contacts. The ${ }^{1} \mathrm{H}-{ }^{15} \mathrm{~N}$ HSQC spectra demonstrate that both mutants are folded in solution (Supplementary Fig. 9a) and FP measurements indicate that these mutations do not substantially affect PHC2 binding to BMI $\left(K_{\mathrm{D}}=0.409 \pm 0.16 \mu \mathrm{M}\right.$ for F189Q BMI1 mutant and $K_{\mathrm{D}}=1.04 \pm 0.25 \mu \mathrm{M}$ for I212E BMI1 mutant) (Fig. 3c). We also validated by NMR and co-immunoprecipitation that the I212E mutant binds PHC2 in a similar manner as the wild-type protein (Supplementary Figs 1 and 9a). To assess whether these point mutations affect the propensity of BMI1 UBL to homo-oligomerize we again employed analytical ultracentrifugation (Fig. 3d). Sedimentation velocity experiments showed that the BMI1 UBL F189Q-PHC2 $2_{1-79}$ complex has concentration dependent sedimentation coefficients similar to the wild-type protein, indicating that this mutant is still able to form higher order oligomers. Interestingly, the sedimentation coefficients of the I212E mutant did not show such concentration dependence (Fig. 3d). This indicates that the I212E mutant has a reduced tendency for oligomerization supporting the second interface as a homo-oligomerization interface of BMI.

We further used NMR to assess whether the I212E mutation blocks the concentration dependent broadening of NMR spectra for the BMI1-PHC2 complex. For this purpose, we titrated ${ }^{15} \mathrm{~N}$ labelled BMI1-PHC2 complex with either unlabelled wild-type or BMI1 I212E-PHC2 complex. As expected, addition of $100 \mu \mathrm{M}$ unlabelled wild-type BMI1-PHC2 complex resulted in significant broadening of the resonances on the HSQC spectrum of $50 \mu \mathrm{M}$ ${ }^{15} \mathrm{~N}$ BMI1-PHC2 (Fig. 3e, Supplementary Fig. 9c,d). On the contrary, addition of $100 \mu \mathrm{M}$ unlabelled BMI1 I212E-PHC2 complex did not cause peak broadening (Fig. 3f, Supplementary Fig. 9c,d). Altogether, both NMR and analytical ultracentrifugation experiments consistently validate that mutation of Ile212 impairs homo-oligomerization of the BMI1-PHC2 complex.

BMI1-PHC2 and BMI-BMI1 interactions regulate PRC1 activity. The PRC1 complex serves as an E3 ubiquitin ligase 


\section{Table 2 | NMR restraints and refinement statistics for the PHC2-BMI1 structure.}

\section{PDB ID}

2NA1

\section{NMR restraints}

Distance constraints

Total NOE

Intra-residue

Inter-residue

Sequential $(|i-j|=1)$

Medium-range $(|i-j|<5)$

Long-range $\mathrm{PHC} 2-\mathrm{PHC} 2(\mid i-j \geq 5)$

Long-range PHC2-BMI1 $(\mid i-j \geq 5)$

Hydrogen bonds

Total dihedral angle restraints

phi

psi

144

43

45

11

16

29

8

26

13

13

Structure statistics

Violations (mean and s.d.)

Distance constraints $(\AA)$

Dihedral angle constraints $\left(^{\circ}\right)$

Max. dihedral angle violation $\left(^{\circ}\right)$

Max. distance constraint violation $(\AA)$

Deviations from idealized geometry

Bond lengths ( $\AA$ )

Bond angles $\left({ }^{\circ}\right)$

Average pairwise r.m.s.d. ${ }^{\star}(\AA)$

Heavy

Backbone

$0.046 \pm 0.114$

$0.070 \pm 0.800$

$1.83 \pm 3.86$

$0.88 \pm 0.09$

0.021

1.8

0.5

0.3

Ramachandran plot summary

Most favoured

Additionally allowed

Generously allowed

Disallowed

BMI1, B cell-specific Moloney murine leukemia virus integration site 1; r.m.s.d., root mean square deviation; $\mathrm{PHC2}$, polyhomeotic homologues.

*Pairwise r.m.s.d. was calculated among 10 refined structures for residues 33-47,127-138,161-231

for histone $\mathrm{H} 2 \mathrm{~A}$, a mark associated with repressed gene transcription ${ }^{22,23}$. We sought to evaluate whether point mutations in the UBL domain that impair either the interactions with $\mathrm{PHC} 2$ or BMI1 homo-oligomerization affect the level of H2A ubiquitination. First, we determined the effect of BMI1 knockdown on the level of histone H2A Lys119 ubiquitination (Ub-H2A) in HeLa cells. We found reduced UbH2A levels on BMI1 knockdown (Fig. 4a), in agreement with the previous report ${ }^{47}$. We next assessed whether overexpression of either wild-type BMI1 or point mutants can rescue $\mathrm{H} 2 \mathrm{~A}$ ubiquitination observed on BMI1 knockdown. HeLa cells transfected with BMI1 small interfering RNA (siRNA) were subsequently transfected with BMI1 variants and the level of UbH2A was analysed by immunoblotting (Fig. 4b, Supplementary Fig. 10). Overexpression of wild-type BMI1 significantly increased $\mathrm{Ub}-\mathrm{H} 2 \mathrm{~A}$ levels, while overexpression of the R165E/H174E or $\mathrm{I} 212 \mathrm{E}$ mutants failed to rescue Ub-H2A levels (Fig. 4b, Supplementary Fig. 10). Interestingly, expression of the I212E mutant strongly decreases $\mathrm{H} 2 \mathrm{~A}$ ubiquitination below the level observed for the control siRNA suggesting a dominant-negative effect. The effect of the F189Q mutant was comparable to wildtype BMI1 suggesting that mutation of this potential homooligomerization interface involving Phe189 has no significant effects on BMI1 function (Fig. 4b, Supplementary Fig. 10). Together, these data demonstrate that point mutations in the BMI1 UBL domain which disrupt protein-protein interactions or homo-oligomerization of BMI1 impair the E3 ubiquitin ligase activity of the PRC1 complex.
BMI1-PHC2 and BMI1-BMI1 interactions regulate BMI1. To further test the functional importance of the BMI1 UBL domain interactions we performed clonogenic survival assays in the human osteosarcoma U2OS cell line. Both BMI1 and PHC2 are expressed at high levels in U2OS cells and have been found to associate with each other in large nuclear structures termed polycomb bodies ${ }^{30,48}$. First, we generated an U2OS cell line expressing inducible BMI1-targeting short hairpin RNA (shRNA; see Methods section). Induction of BMI1 shRNA expression significantly reduced BMI1 protein levels (Fig. 4c) and resulted in $\sim 25 \%$ reduction in colony numbers when compared to the cells expressing non-silencing shRNA (Fig. 4d, e). We then tested the effect of overexpression of either wild-type BMI1 or the point mutants (Supplementary Fig. 11). Overexpression of wild-type BMI1 significantly rescued the clonogenic potential of U2OS cells (Fig. 4f,g). On the contrary, overexpression of either R165E/H174E or I212E mutants did not rescue the clonogenic potential of U2OS cells expressing BMI1 shRNA. Expression of these two variants of BMI1 significantly decreased colony numbers when compared to wild-type BMI1, again supporting that R165E/H174E and I212E mutants function as dominant negatives (Fig. 4f,g) possibly through activity of additional PCGF members. Since the mutations in BMI1 are introduced in the UBL domain, we expect that both BMI1 variants retain the interaction with RING1A/B proteins via the $\mathrm{N}$-terminal RING domain. Therefore, the strong reduction in clonogenic potential of U2OS cells results from the loss of interaction with PHC2 or from the disruption of BMI1 homo-oligomerization. Expression of the F189Q mutant did not fully rescue the clonogenic activity of BMI1 knockdown cells, suggesting that this mutation also partially impairs BMI1 function; although to a much weaker extent compared to R165E/ H174E or I212E mutants.

\section{Discussion}

BMI1 is an essential component of the canonical polycomb repressive complex 1 (PRC1) that participates in $\mathrm{H} 2 \mathrm{~A}$ ubiquitin ligase activity 26,27 and in protein-protein interactions stabilizing the overall architecture of PRC1 (refs 29,30). In this study, we found that the central domain of BMI1 has an ubiquitin-like (UBL) fold and plays a dual role in maintaining protein-protein interactions within PRC1. First, the UBL domain interacts with the polyhomeotic protein $\mathrm{PHC} 2$, a member of the canonical PRC1. Second, the UBL domain is involved in homo-oligomerization of BMI1. Employing functional studies we validated that both of these activities mediated via the UBL domain are essential for BMI1 function.

Our work supports previous studies demonstrating that the UBL domain of BMI1 is involved in protein-protein interactions and is essential for the oncogenic activity of BMI1 (refs 36-38). Here, we mapped a 24 amino acid fragment of PHC2 that binds to BMI1 with a submicromolar affinity $\left(K_{\mathrm{D}}=398 \mathrm{nM}\right)$ and $1: 1$ stoichiometry. We determined the structure of BMI1 in complex with PHC2 and found that the UBL domain recognizes a disordered fragment of $\mathrm{PHC} 2$ that adopts a hairpin conformation on binding. Such architecture of the BMI1-PHC2 interaction involving the UBL domain is conserved among other proteinprotein interactions of polycomb proteins, including the RING1BCBX7, RING1B-RYBP and PCGF1-BCOR complexes ${ }^{41,49}$.

Sequence alignment of BMI1 homologues (PCGF family) shows that the UBL domain of BMI1 is most similar to MEL18 (PCGF2) with 60\% sequence identity, while it differs significantly from the remaining homologues (Supplementary Fig. 12a,b). To assess whether the MEL18 UBL domain interacts with PHC2 we tested the binding of MEL18 $8_{121-237}$ fragment with $\mathrm{PHC}_{32-61}$ 
a

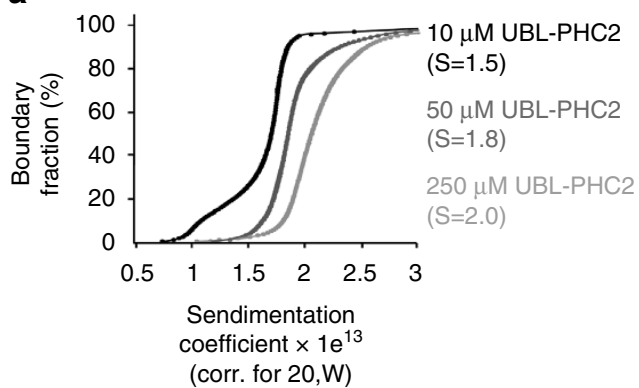



C

$$
\begin{array}{ll}
\text { UBL } & \left(K_{\mathrm{D}}=215 \mathrm{nM}\right) \\
\mathrm{F} 189 \mathrm{Q} & \left(K_{\mathrm{D}}=409 \mathrm{nM}\right) \\
\text { I212E } & \left(K_{\mathrm{D}}=1,040 \mathrm{nM}\right)
\end{array}
$$



d



F189Q



Sendimentation coefficient $\times 1 \mathrm{e}^{13}$ (corr. for $\left.20, \mathrm{~W}\right)$

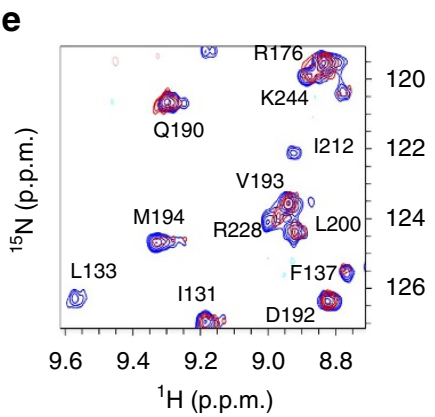

f

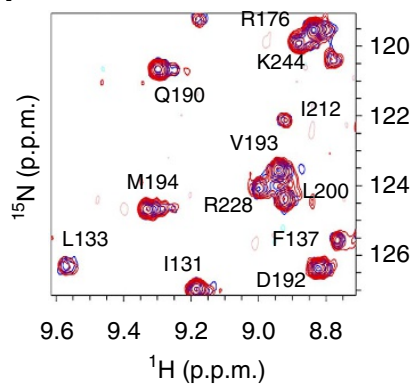

Figure 3 | BMI1 UBL forms higher order oligomers in solution. (a) Van Holde-Weischet [G(s)] plots of sedimentation distributions for wild-type BMI1 UBL-PHC2 $1-79$ complex showing a concentration dependent increase in particle size in solution. Values of sedimentation coefficients are in parenthesis. (b) The crystal structure of the BMI1 UBL domain showing two putative homo-oligomerization interfaces identified based on crystal packing. Residues selected for mutation to block homo-oligomerization are labelled. (c) Binding affinities of BMI1 variants with $\mathrm{PHC2}_{1-79}$ determined using fluorescence polarization experiments titrating FITC-PHC2 $32-61$ with wild-type BMI1 UBL or point mutants. Experiments were performed in duplicates, error bars represent s.d.; $K_{D}$ is reported as the average and s.d. from three independent experiments. (d) Van Holde-Weischet [G(s)] plots of sedimentation distributions for BMI1 UBL-PHC2 ${ }_{1-79}$ complexes at 10 and $50 \mu \mathrm{M}$ comparing the wild-type BMI1 and point mutants F189Q and I212E. (e) Superposition of ${ }^{1} \mathrm{H}-^{15} \mathrm{~N} \mathrm{HSQC}$ spectra for $50 \mu \mathrm{M}{ }^{15} \mathrm{~N}$ BMI1 UBL-PHC2 $33-56$ complex in the absence (blue) and presence of $100 \mu \mathrm{M}$ unlabelled BMI1 UBL-PHC2 $33-56$ complex (red). (f) Superposition of ${ }^{1} \mathrm{H}_{-}{ }^{15} \mathrm{~N}$ HSQC spectra for $50 \mu \mathrm{M}{ }^{15} \mathrm{~N}$ BMI1 UBL-PHC2 $33-56$ complex in the absence (blue) and presence of $100 \mu \mathrm{M}$ unlabelled BMI1 UBL I212E-PHC2 $33-56$ complex (red).

using the FP assay. We found that MEL18 binds PHC2 with slightly reduced affinity $\left(K_{\mathrm{D}}=812 \pm 9.0 \mathrm{nM}\right)$ when compared to BMI1 (Supplementary Fig. 12c). Analysis of the BMI1-PHC2 structure revealed that all BMI1 residues involved in contacts with PHC2 are identical with MEL18 and strongly suggests very similar binding mode for MEL18-PHC2. Sequences of the remaining homologues of BMI1 differ significantly and most likely they do not interact with PHC proteins.

Our studies identified that BMI1 has a propensity to form homo-oligomers in solution. We employed analytical ultracentrifugation to demonstrate that BMI1 UBL domain undergoes concentration dependent oligomerization. Analysis of the crystal packing for the BMI1-PHC2 structure suggested two possible homo-oligomerization interfaces, one of which harboring Ile212 was validated through mutagenesis studies. Interestingly, our finding is consistent with the previous observations that full length RING1B and BMI1 form a heterotetramer in vitro ${ }^{26}$.

Structure determination of the BMI1-PHC2 complex represented a significant technical challenge. Previous attempts at structural studies of the BMI1 UBL domain were hampered by protein instability ${ }^{41}$. To design constructs of BMI1 and PHC2 suitable for structural studies we employed ${ }^{13} \mathrm{C}$-detected $\mathrm{NMR}$ experiments to identify disordered protein fragments ${ }^{39}$. Using such an approach we efficiently mapped the minimal folded fragments of BMI1 and $\mathrm{PHC} 2$ involved in this interaction highlighting the utility of this methodology in designing constructs for structural biology 39 . Furthermore, structure determination of the BMI1-PHC2 complex solely by either X-ray crystallography or solution NMR was hampered by additional challenges, such as crystallographic artifacts from the crystal packing, low protein solubility and high propensity for aggregation. To resolve these difficulties we used a Rosetta-based joint refinement method incorporating the crystal structure of the BMI1 UBL domain and NMR restraints defining UBL-PHC2 contacts. While joint refinement using both methods has been used before to improve structure accuracy ${ }^{50-53}$; to our knowledge, our work represents a unique example where X-ray crystallography data for a protein-protein complex were not sufficient for structure determination and NMR restraints were required to determine the overall structure of the complex. 
a

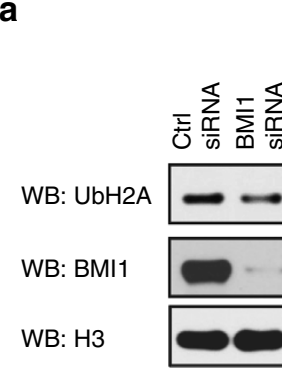

b

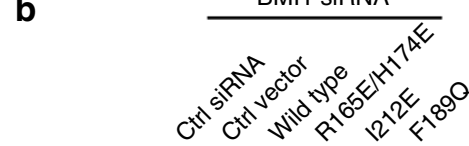

WB: UbH2A

WB: BMI1

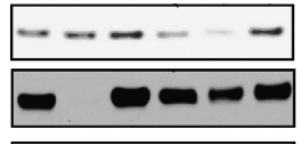

WB: $\beta$-actin

WB: Flag

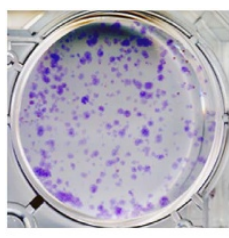

Ctrl shRNA



BMI1 ShRNA

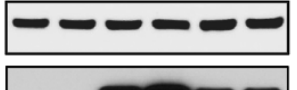

2
C

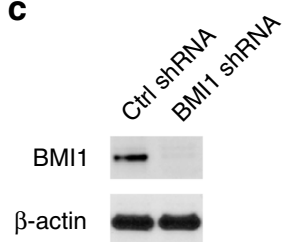

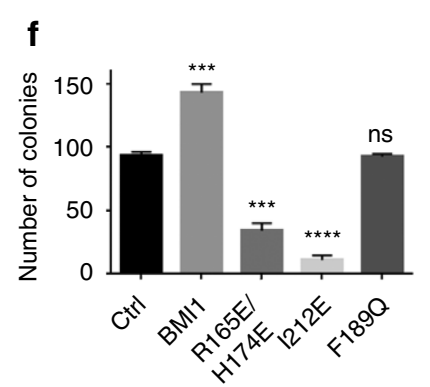

g

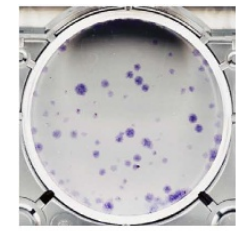

Ctrl

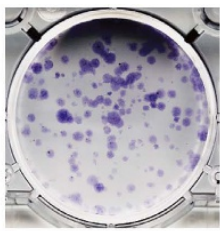

BMI1

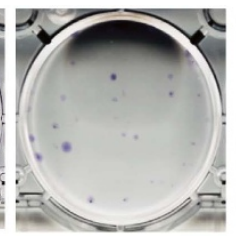

R165E/H174E

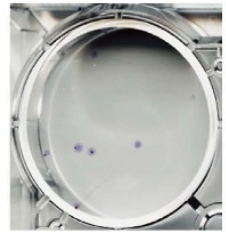

I212E



F189Q

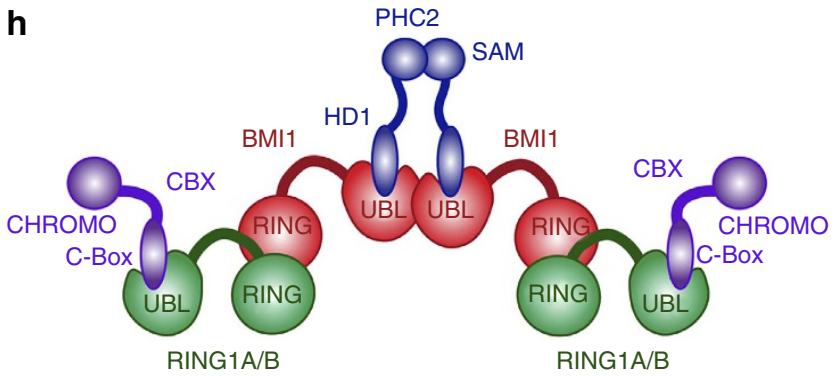

Figure 4 | Functional consequences of disrupting BMI1 protein-protein interactions and homo-oligomerization. (a) Analysis of the effect of BMI1 knockdown on Ub-H2A levels in HeLa cells. HeLa cells were transfected with control or BMI1 3' UTR siRNA and followed by immunoblot analysis $48 \mathrm{~h}$ post transfection. (b) Characterization of Ub-H2A levels on overexpression of BMI1 mutants in HeLa cells. HeLa cells transfected with control or BMI1 3' UTR siRNA for $48 \mathrm{~h}$ were transfected with plasmids encoding Flag-tagged full length wild-type BMI1 or three mutants and analysed using immunoblotting after $48 \mathrm{~h}$. (c) Inducible knockdown of BMI1 in U2OS cells using shRNA. U2OS cells carrying control or BMI1 shRNA were treated with doxycycline for $96 \mathrm{~h}$ and cell lysates were analysed for BMI1 expression levels. (d) Quantification of colony numbers from the clonogenic survival assay in panel e demonstrating the effect of BMI1 knockdown on clonogenic potential of U2OS cells. U2OS cells were plated in triplicates and incubated for 14 days. Error bars represent s.d. of triplicate wells; ${ }^{\star} P \leq 0.05$. (e) Representative plates from clonogenic survival assays on BMl1 knockdown in U2OS cells. (f) Quantification of the clonogenic survival assay in panel $\mathbf{g}$ demonstrating the effect of re-expression of BMI1 mutants in U2OS cells expressing BMI1 shRNA. Error bars represent s.d. of triplicate wells; ${ }^{\star \star \star} P \leq 0.001 ;{ }^{\star \star \star \star} P \leq 0.0001$; ns, not significant. (g) Representative plates from the clonogenic survival assay on BMI1 knockdown and reexpression of BMI1 mutants in U2OS cells. (h) Proposed architecture of the PRC1 complex.

On the basis of our structural studies, we generated and characterized point mutations in the BMI1 UBL domain, which disrupt the interaction with polyhomeotic proteins as well as BMI1 UBL homo-oligomerization. The BMI1 R165E/H174E double mutant has significantly reduced binding to PHC2 and the I212E mutant has strongly decreased propensity to homo-oligomerize. We found that both mutants impair the activity of PRC1 to ubiquitinate H2A in HeLa cells. Furthermore, knockdown of BMI1 followed by re-expression of BMI1 R165E/ H174E or I212E mutants strongly decreases the clonogenic potential of U2OS cells. These findings emphasize that both the protein-protein interactions and oligomerization mediated through the UBL domain are necessary for BMI1 function. The point mutations we characterized provide a potential tool which might be further explored to dissect functional implications of disrupting the BMI1 interactions.

Our structural studies established an important role of BMI1 in coordinating the architecture of the canonical PRC1 complex. BMI1 is a key structural component of the PRC1 that simultaneously interacts with RING1A/B and PHC proteins 
bridging the $\mathrm{H} 2 \mathrm{~A}$ ubiquitin ligase activity of RING1A/B and the polyhomeotic subunit (Fig. 4h). The interaction of the BMI1 UBL domain with PHC proteins is essential for the proper assembly of the PRC1 complex which is needed for ubiquitination of $\mathrm{H} 2 \mathrm{~A}$ in cells. To further validate this, we have performed knockdown of PHC2 and PHC3 and found a very significant loss of $\mathrm{H} 2 \mathrm{~A}$ ubiquitination in HeLa cells on simultaneous loss of PHC proteins (Supplementary Fig. 13). We also found that the BMI1 UBL domain may represent a motif contributing to the oligomerization of PRC1. While BMI1 UBL homo-oligomerization is relatively weak in vitro, the UBL domain may function in concert with SAM domains, a well-known oligomerization motif in the PHC subunit (Fig. 4h) $)^{54}$, which is likely involved in PRC1 clustering ${ }^{40}$. As previously suggested, $\mathrm{PRC1}$ may regulate gene expression by compacting chromatin through interactions between distinct PRC1 complexes at either local or distal nucleosomes ${ }^{24,40}$. Here we propose a model where the homo-oligomerization properties of BMI1 enhance the higher order architecture of PRC1 (Fig. 4h).

Emerging studies suggest that BMI1 is a promising target for the development of anti-cancer therapeutics ${ }^{16}$. Detailed characterization of BMI1 protein-protein interactions will support the design of efficient strategy to reverse the oncogenic activity of BMI1. The structure of the PHC2-BMI1 complex we determined here provides the molecular basis to develop small molecule inhibitors of BMI1 activity and might pave the way towards novel anti-cancer therapeutics.

\section{Methods}

Plasmid construction. cDNA encoding BMI $1_{106-240}$, BMI1 $1_{121-235}$ and MEL18 ${ }_{121-237}$ (ordered from Life Technologies) and full-length PHC2_B (a kind gift from Dr Jeff Rual, UM Pathology) were subcloned into a modified pET32a vector with a $\mathrm{N}$-terminal $\mathrm{His}_{6}$-thioredoxin expression tag and PreScission protease cleavage site. The cDNA encoding the PHC2 $30-64-\mathrm{BMI}_{121-235}$ fusion was ordered from Life Technologies and subcloned into the same vector. The mammalian expression vectors for pCMV BMI1 and PHC2 constructs were prepared from CDNA using standard subcloning techniques. The genes for the E. Coli BirA biotin ligase and Avi-BMI1 ${ }_{106-326}$ were ordered from Genscript and Life Technologies, respectively, and subcloned into the pCMV vector. Mutant constructs were generated using QuikChange site-directed mutagenesis protocol (Agilent).

Protein expression and purification. BMI1 UBL domain variants, MEL18 UBL domain and PHC2-BMI1 fusion were expressed in Codon + BL21 (DE3) E. coli cells (Sigma) with an N-terminal $\mathrm{His}_{6}$ - thioredoxin tag. Cells were grown in Luria broth or labelled M9 medium with ampicillin selection. After $16 \mathrm{~h}$ induction with $0.5 \mathrm{mM}$ IPTG at $18^{\circ} \mathrm{C}$ cells were resuspended in lysis buffer $(50 \mathrm{mM}$ tris, pH 7.5 at $25^{\circ} \mathrm{C}, 250 \mathrm{mM} \mathrm{NaCl}, 20 \mathrm{mM}$ Imidazole, $0.5 \mathrm{mM}$ phenylmethylsulfonyl fluoride (PMSF), $1 \mathrm{mM} \beta$-mercaptoethanol ( $\beta$-ME) and lysed using a cell disrupter. Clarified lysate was applied to a HisTrap HP (GE Healthcare) and eluted with lysis buffer containing $0.5 \mathrm{M}$ imidazole. To remove the $\mathrm{His}_{6}$ - thioredoxin tag, the protein was cleaved with PreScission protease and BMI1 constructs were further purified using cation exchange chromatography. Purified protein was buffer exchanged into storage buffer ( $100 \mathrm{mM}$ bis tris, $\mathrm{pH} 6.5,50 \mathrm{mM} \mathrm{NaCl}, 1 \mathrm{mM}$ TCEP) using HiPrep Desalting Column (GE Healthcare). For crystallization, BMI1 was incubated with two-fold excess of a synthetic $\mathrm{PHC}_{33-56}$ peptide (Genscript) and applied to a Superdex S75 gel filtration column (GE Healthcare) pre-equilibrated with storage buffer.

$\mathrm{PHC}_{1-79}$ was expressed in BL21 (DE3) E. coli cells (Sigma) with an N-terminal $\mathrm{His}_{6}$ - thioredoxin tag. Cells were grown in Luria broth or labelled M9 medium with ampicillin selection. After $16 \mathrm{~h}$ induction with $0.5 \mathrm{mM}$ IPTG at $18^{\circ} \mathrm{C}$ cells were resuspended in lysis buffer $\left(50 \mathrm{mM}\right.$ tris, $\mathrm{pH} 7.5$ at $25^{\circ} \mathrm{C}, 250 \mathrm{mM} \mathrm{NaCl}, 20 \mathrm{mM}$ imidazole, $0.5 \mathrm{mM}$ phenylmethylsulfonyl fluoride (PMSF), $1 \mathrm{mM} \beta$-mercaptoethanol $(\beta-\mathrm{ME}))$ and lysed using a cell disrupter. Clarified lysate was applied to a HisTrap HP (GE Healthcare) and eluted with lysis buffer containing $0.5 \mathrm{M}$ imidazole. The $\mathrm{His}_{6^{-}}$thioredoxin tag was cleaved with PreScission protease during dialysis against 100 -fold excess dialysis buffer ( $50 \mathrm{mM}$ tris, $50 \mathrm{mM} \mathrm{NaCl}, 1 \mathrm{mM}$ TCEP at $\mathrm{pH} 7.5$ ) and separated from $\mathrm{PHC}_{1-79}$ by nickel affinity. $\mathrm{PHC}_{1-79}$ was further purified by Superdex S75 gel filtration (GE Healthcare) pre-equilibrated with storage buffer (50 $\mathrm{mM}$ phosphate, $\mathrm{pH} 6.5,50 \mathrm{mM} \mathrm{NaCl}, 1 \mathrm{mM}$ TCEP).

Isothermal titration calorimetry. The measurements were performed using a VP-ITC titration calorimetric system (MicroCal) at $25^{\circ} \mathrm{C}$. BMI $1_{121-235}$ and trx-PHC2 $2_{1-79}$ were dialysed extensively against ITC buffer $(50 \mathrm{mM}$ phosphate, $\mathrm{pH}$ 6.5, $50 \mathrm{mM} \mathrm{NaCl}, 1 \mathrm{mM}$ TCEP). Peptide PHC2 ${ }_{33-56}$ (Genscript) was directly dissolved in ITC buffer. All samples were degassed before measurements. For measurement of $\mathrm{BMI} 1_{121-235}-\mathrm{PHC}_{1-79}$ interaction the calorimetric cell, containing BMI1 $(22 \mu \mathrm{M})$, was titrated with trx-PHC2 $2_{1-79}(164 \mu \mathrm{M})$ injected in $10 \mu \mathrm{l}$ aliquots. For measurement of $\mathrm{BMI} 1_{121-235}-\mathrm{PHC} 2_{33-56}$ interaction the calorimetric cell, containing BMI $1(9 \mu \mathrm{M})$, was titrated with $\mathrm{PHC}_{33-56}(100 \mu \mathrm{M})$ injected in $10 \mu \mathrm{l}$ aliquots. Data were analysed using Origin 7.0 (OriginLab) to obtain $\mathrm{K}_{\mathrm{D}}$ and stoichiometry.

Protein NMR experiments. Samples for assignment of ${ }^{13} \mathrm{C}^{15} \mathrm{~N}-\mathrm{BMI}{ }_{106-240}$ contained $70 \mu \mathrm{M}$ protein in NMR buffer $(50 \mathrm{mM}$ bis tris, $\mathrm{pH} 6.5,50 \mathrm{mM} \mathrm{NaCl}$, $1 \mathrm{mM}$ TCEP and $\left.5 \% \mathrm{D}_{2} \mathrm{O}\right) .2 \mathrm{D}{ }^{13} \mathrm{C}$-detected CACO, CBCACO and CANCO experiments were used for carbon assignment of flexible residues ${ }^{55}$. Samples for assignment of $\mathrm{PHC}_{1-79}$ contained $60 \mu \mathrm{M}{ }^{13} \mathrm{C}^{15} \mathrm{~N}-\mathrm{PHC} 2_{1-79}$ in a buffer containing $100 \mathrm{mM}$ bis tris, $\mathrm{pH} 6.5,100 \mathrm{mM} \mathrm{NaCl}, 1 \mathrm{mM}$ TCEP and $5 \% \mathrm{D}_{2} \mathrm{O} .2 \mathrm{D}{ }^{13} \mathrm{C}$-detected CACO, CBCACO and CANCO experiments were used for carbon assignment ${ }^{55}$ Mapping the PHC2 motif involved in BMI binding was performed for $60 \mu \mathrm{M}$ ${ }^{13} \mathrm{C}^{15} \mathrm{~N}-\mathrm{PHC} 2_{1-79}$ mixed with $60 \mu \mathrm{M}$ BMI1 UBL. BMI1 UBL-PHC2 binding experiments contained $50-100 \mu \mathrm{M}^{15} \mathrm{~N}$-labelled wild-type $\mathrm{BMI} 1_{121-235}$ or mutants and unlabelled $\mathrm{PHC}_{33-56}$. Analysis of peak broadening and aggregation was performed by titration of $50 \mu \mathrm{M}^{15} \mathrm{~N}$-labelled BMI $1_{121-235}$ in complex with $\mathrm{PHC}_{33-56}$ with 50 and $100 \mu \mathrm{M}$ unlabelled $\mathrm{BMI}_{121-235}$ wild-type or I212E$\mathrm{PHC}_{33-56}$ complex. All NMR spectra were acquired at $303 \mathrm{~K}$ on a $600 \mathrm{MHz}$ Bruker Advance III spectrometer equipped with cryoprobe, running Topspin version 2.1. Spectra processing and visualization were performed using NMRPipe ${ }^{56}$ and Sparky 57

Crystallization and structure determination. Initial crystals were obtained through sitting drop screening of $\mathrm{BMI}_{121-235}-\mathrm{PHC} 2_{33-56}$ complex purified using size exclusion. Crystals were further optimized by hanging-drop vapor diffusion with equal volumes $(1 \mu \mathrm{l})$ of protein $(9 \mathrm{mg} / \mathrm{ml}$ in $50 \mathrm{mM}$ bis tris, $\mathrm{pH} 6.5,50 \mathrm{mM} \mathrm{NaCl}$, $1 \mathrm{mM}$ TCEP) and the precipitant solution (100 mM MES, pH 6.5, $50 \mathrm{mM} \mathrm{MgCl}, 7 \%$ isopropanol, 6\% PEG 4000). Crystals formed within 7 days at $4{ }^{\circ} \mathrm{C}$. Crystals were cryoprotected using the precipitant solution containing $20 \%$ glycerol and flash frozen in liquid nitrogen. X-ray diffraction data of crystals were collected at a resolution of $2.5 \AA$ at the Advanced Photon Source at LS-CAT beam line 21-ID-F. The data were indexed, integrated, and scaled using the HKL2000 suite ${ }^{58}$. The structure was determined by molecular replacement method with the CCP4 version of MOLREP 59 using the polycomb group Ring finger protein complex structure (PDB code 4HPM $\mathrm{B}$ chain) as a search model ${ }^{41}$. Model building was performed manually using the program WinCoot ${ }^{60}$ and the refinement was performed with CCP4 refmac5 (ref. 61). The data statistics are summarized in Table 1.

Structure determination using joint NMR and X-ray refinement.

NMR experiments for structure determination were collected for $200 \mu \mathrm{M}$ ${ }^{13} \mathrm{C}^{15} \mathrm{~N}-\mathrm{PHC} 2_{30-64}-\mathrm{BMI}_{121-235}$ fusion protein in $50 \mathrm{mM}$ bis tris, $\mathrm{pH} 6.5$ buffer with $50 \mathrm{mM} \mathrm{NaCl}, 1 \mathrm{mM}$ TCEP and $5 \% \mathrm{D}_{2} \mathrm{O}$. Backbone assignment was completed based on a series of triple-resonance experiments including HNCACB, CBCA (CO)NH, HNCA, HN(CO)CA, HNCO and HN(CA)CO. Methyl side chain resonances were assigned using $3 \mathrm{D}^{13} \mathrm{C}^{-1} \mathrm{H}_{-}^{1} \mathrm{H}$ HCCH-TOCSY. Distance restraints were obtained from 3D ${ }^{15} \mathrm{~N}$-separated NOESY-HSQC and $3 \mathrm{D}{ }^{13} \mathrm{C}$-separated NOESY-HSQC spectra measured with $150 \mathrm{~ms}$ mixing time. Initial structures were calculated in CYANA ${ }^{42}$ based on distance restraints from NOESY spectra and dihedral angle restraints from TALOS + (ref. 62). NMR structures of PHC2 were combined with the X-ray crystal structure of BMI1 UBL domain and the entire complex was refined using Rosetta ${ }^{43,44,63}$ constrained by NOE-derived distances restraints, dihedral angle restraints and BMI1 crystal structure coordinates. BMI1 was restricted during refinement with the exception of loop residues 121-127 and 138-160 which were missing in the crystal structure. These fragments were added using the loop building protocol ${ }^{64}$ and were treated as disordered fragments during Rosetta refinement. Side chains of BMI1 residues 160-178 were unrestricted during the refinement. Data statistics are summarized in Table 2.

Fluorescence polarization assays. Dissociation constants for binding of $\mathrm{PHC} 2$ to BMI1 UBL domain variants and MEL18 UBL were determined by fluorescence polarization. Fluorescein-labelled $\mathrm{PHC}_{32-61}$ (Genscript) at $20 \mathrm{nM}$ was titrated with a range of BMI1 or MEL18 concentrations in the FP buffer $(50 \mathrm{mM}$ bis tris, $\mathrm{pH} 7.5$, $50 \mathrm{mM} \mathrm{NaCl}, 1 \mathrm{mM}$ TCEP, $0.01 \%$ BSA, $0.25 \%$ tween-20). After $1 \mathrm{~h}$ incubation of the protein-peptide complexes, changes in fluorescence polarization and anisotropy were measured at $525 \mathrm{~nm}$ after excitation at $495 \mathrm{~nm}$ using PHERAstar microplate reader (BMG). Results were used to calculate binding affinity $\left(K_{\mathrm{D}}\right)$ for PHC2 with wild-type BMI1, BMI1 mutants, or MEL18 using the Prism 4.0 (GraphPad) program

Analytical ultracentrifugation. Sedimentation velocity experiments were performed on a Beckman Optima XL-I at the Center for Analytical Ultracentrifugation of Macromolecular Assemblies (CAUMA) at the University of Texas Health Center at San Antonio. Calculations were performed with the UltraScan software ${ }^{65}$ at the Texas Advanced Computing Center at the University of Texas at Austin and at the Bioinformatics Core Facility at the University of Texas 
Health Science Center at San Antonio. Protein samples were prepared by mixing BMI1 UBL with $\mathrm{PHC}_{1-79}$ followed by size exclusion to purify 1:1 stoichiometric complex. Samples were subsequently concentrated to 10,50 or $250 \mu \mathrm{M}$ in a $50 \mathrm{mM}$ phosphate buffer, $\mathrm{pH} 6.5$ containing $50 \mathrm{mM} \mathrm{NaCl}$ and $1 \mathrm{mM}$ TCEP. All analytical ultracentrifugation data were collected at $20^{\circ} \mathrm{C}$ and spun at 50 k r.p.m., using standard Epon-2 channel centerpieces. All data were first analysed by two-dimensional spectrum analysis with simultaneous removal of time-invariant noise ${ }^{66}$ and then by enhanced van Holde-Weischet analysis ${ }^{67}$ and genetic algorithm refinement ${ }^{68}$ where applicable, followed by Monte Carlo analysis 69 .

Cell cultures. Human embryonic kidney-293 (HEK293) (CRL-1573) cell line, cervical carcinoma cell line (HeLa) (CCL-2) and osteosarcoma cell line U2OS (HTB-96) were obtained from the American Type Culture Collection and were cultured either in Dulbecco's modified Eagle's medium (for HEK293 and HeLa) or McCoy's 5a Medium Modified (for U2OS) supplemented with 10\% FBS. For plasmid transfection, Lipofectamine 2000 (Invitrogen) and, for the siRNA transfection, Lipofectamine RNAi-max (Invitrogen) were used according to the manufacturer's instructions.

Pull-down and co-immunoprecipitation experiments. HEK293 cells were transfected with BirA, Myc-PHC2_B and Avi-BMI1 $1_{106-326}$ constructs using Fugene 6 (Roche) transfection agent. Cells were harvested by centrifugation $48 \mathrm{~h}$ after transfection and lysed through sonication in lysis buffer (50 mM HEPES, pH 7.5, $150 \mathrm{mM} \mathrm{NaCl}, 1 \mathrm{mM}$ EDTA, $2.5 \mathrm{mM}$ EGTA, $1 \mathrm{mM}$ NEM, $1 \mathrm{mM} \mathrm{NaF}, 0.1 \mathrm{M}$ $\mathrm{Na}_{3} \mathrm{VO}_{4}, 10 \%$ glycerol, $0.1 \mathrm{mM} \beta$-glycerophospate, $0.01 \% \mathrm{NP}-40$ ) with protease inhibitor cocktail (Sigma). Lysate was clarified by centrifugation and streptavidin magnetic beads (Pierce) were added to each sample and incubated at $4{ }^{\circ} \mathrm{C}$ with rotation for $16 \mathrm{~h}$. Beads were washed 4 times with wash buffer $(20 \mathrm{mM}$ tris, $\mathrm{pH} 8.0$, $300 \mathrm{mM} \mathrm{KCl}, 1 \mathrm{mM}$ EDTA, $10 \%$ glycerol, $0.1 \%$ NP-40) with protease inhibitor cocktail (Sigma) and proteins were boiled in Lammeli buffer. Samples were analysed by SDS-PAGE and western blotting probed with either Myc antibody (Cell Signaling, catalog \#2276S) or BMI1 antibody (Millipore, catalog \#05-637). $10 \%$ of the total protein used for pulldown was taken as input control. Uncropped images of the western blots are shown in Supplementary Fig. 14.

For co-immunoprecipitation experiments HEK293 cells were transfected with full length Flag-tagged BMI1, R165E/H174E, I212E mutants and Myc-PHC2_B constructs using lipofectamine 2000 (Invitrogen). After $48 \mathrm{~h}$ incubation, cells were harvested and lysed and processed as described above. Flag-M2 dynabeads (Sigma) were washed in lysis buffer and added to each sample and incubated at $4{ }^{\circ} \mathrm{C}$ with rotation overnight. Beads were washed 3 times with lysis buffer and boiled in $1 \%$ SDS. Samples were mixed with Lammeli buffer, boiled and were analysed by SDSPAGE and western blotting with Myc (Cell Signaling), Flag (Sigma, catalog \#F3165), BMI1 (Millipore) and $\beta$-Actin antibodies. $10 \%$ of the total protein used for immunoprecipitation was used as an input control.

Lentiviral shRNA-mediated gene knockdown. Control and BMI1 shRNA expressing U2OS stable transfectant cells were generated using Inducible TRIPZ Lentiviral shRNA system from Dharmacon. Briefly, various individual clones targeting different regions of BMI1 (Clone ID; V2THS_48576, V2THS_244779, V3THS_400015, V3THS_302126) and non-silencing control (shRNA) lentiviral constructs were obtained, packaged and lentiviral particles were produced as per manufacturer's instructions. U2OS cells transduced with individual constructs were continuously cultured in puromycin to select for cells containing the constructs. Stable U2OS cells were incubated in Doxycycline $\left(1 \mu \mathrm{g} \mathrm{ml}^{-1}\right)$ for $48 \mathrm{~h}$ before assessment for \% RFP expression to confirm presence of lentiviral DNA. Based on knockdown efficiency of BMI1, as determined by RFP expression and quantitative real time PCR, U2OS cells carrying BMI1 V3THS_400015 clone was selected for further analysis.

BMI1 knockdown and analysis of ubH2A in HeLa cells. 100,000 HeLa cells were reverse transfected with $25 \mathrm{nM}$ of BMI1 $3^{\prime} \mathrm{UTR}$ siRNA (Dharmacon) for $48 \mathrm{~h}$ using lipofectamine RNAiMax (Invitrogen) as per manufacturer instructions in 6 well plate. After $48 \mathrm{~h}$ of siRNA transfection, medium was replaced and BMI1 wild-type or mutant constructs were transfected using lipofectamine 2000 (Invitrogen) as per manufacturer protocol. Cells were incubated for $48 \mathrm{~h}$ before washing, trypsinization and lysis. Equal amounts of whole cell lysate were separated on 10\% SDS-PAGE gels. Blots were probed with primary antibodies (H2Aub(K119), Cell Signaling Technology, catalog \#8240S; BMI1, Millipore; $\beta$-Actin, EMD Millipore, catalog \#04-1116; H3, Abcam, catalog \#ab1791) overnight at $4{ }^{\circ} \mathrm{C}$, washed five times in TBS plus $0.1 \%$ Tween (TBST) and then incubated with the appropriate horseradish peroxidase-conjugated secondary antibody for $1 \mathrm{~h}$ at room temperature. Membranes were washed five times in TBST and visualized on autoradiography film after incubating with ECL reagent (ECL Prime, GE Healthcare). Uncropped images of the western blots are shown in Supplementary Fig. 14.

siRNA mediated PHC2/PHC3 knockdown in HeLa cells. For PHC2 and PHC3 knockdown 100,000 HeLa cells were reverse transfected with either $50 \mathrm{nM}$ of PHC2 and PHC3 siRNAs individually (Dharmacon) or in combination for $96 \mathrm{~h}$ using Lipofectamine RNAiMax as per manufacturer instructions. Equal amounts of whole cell lysate were separated on 10\% SDS-PAGE gels. Blots were probed with primary antibodies (H2Aub(K119), Cell Signaling Technology; H3 (Abcam); $\beta$-actin, EMD Millipore). PHC2 and PHC3 siRNA mediated knockdown efficiency was measured by quantitative real time PCR. Uncropped images of the western blots are shown in Supplementary Fig. 14.

Clonogenic survival assay. Clonogenic survival assays were performed using techniques described previously ${ }^{70}$. Briefly, U2OS cells containing control or BMI1 shRNA, were incubated with Doxycycline $\left(1 \mathrm{mg} \mathrm{m}^{-1}\right)$ for $48 \mathrm{~h}$ to induce shRNA expression. After $48 \mathrm{~h}$ incubation, cells were transfected with BMI1 wild-type or mutant DNA using lipofectamine 2000 (Invitrogen) as per manufacturer protocol for another $48 \mathrm{~h}$. On completion of $48 \mathrm{~h}$ with DNA transfection, cells were washed with PBS twice, trypsinized, counted and plated at low density (500 cells each well) in triplicates in 6 well plates and left to grow for 14 days at $37^{\circ} \mathrm{C}$. On the 14th day plates were fixed with methanol-acetic acid, stained with crystal violet, and scored for colonies containing more than 50 cells to assess the colony-forming ability. Error bars are from triplicate samples. Differences between control and BMII wild-type or mutant samples were analysed by unpaired $t$-test and $P$ values were estimated based on this model. Significance was determined based on a significance level of 0.05 . Remaining cells were used for whole cell lysate isolation and immunoblotting analysis to determine extent of BMI1 knockdown and to confirm overexpression of BMI1 DNA constructs.

Data availability. The atomic coordinates and structure factors for the BMI1 UBL domain and the PHC2-BMI1 complex have been deposited in the PDB with accession codes: 5FR6 and 2NA1. The data that support the findings of this study are available within the article and its Supplementary Information files, or available from the corresponding author on request.

\section{References}

1. Haupt, Y., Alexander, W. S., Barri, G., Klinken, S. P. \& Adams, J. M. Novel zinc finger gene implicated as myc collaborator by retrovirally accelerated lymphomagenesis in E mu-myc transgenic mice. Cell 65, 753-763 (1991).

2. Lessard, J. \& Sauvageau, G. Bmi-1 determines the proliferative capacity of normal and leukaemic stem cells. Nature 423, 255-260 (2003).

3. Mihara, K. et al. Bmi-1 is useful as a novel molecular marker for predicting progression of myelodysplastic syndrome and patient prognosis. Blood 107, 305-308 (2006).

4. Mohty, M., Yong, A. S., Szydlo, R. M., Apperley, J. F. \& Melo, J. V. The polycomb group BMI1 gene is a molecular marker for predicting prognosis of chronic myeloid leukemia. Blood 110, 380-383 (2007).

5. Chowdhury, M. et al. Expression of Polycomb-group (PcG) protein BMI-1 predicts prognosis in patients with acute myeloid leukemia. Leukemia 21, 1116-1122 (2007).

6. Song, L. B. et al. Bmi-1 is a novel molecular marker of nasopharyngeal carcinoma progression and immortalizes primary human nasopharyngeal epithelial cells. Cancer Res. 66, 6225-6232 (2006).

7. Wang, Y. et al. Cancer stem cell marker Bmi-1 expression is associated with basal-like phenotype and poor survival in breast cancer. World J. Surg. 36, 1189-1194 (2012).

8. Cooper, A. et al. Ewing tumors that do not overexpress BMI-1 are a distinct molecular subclass with variant biology: a report from the Children's Oncology Group. Clin. Cancer Res. 17, 56-66 (2011).

9. Rizo, A. et al. Repression of BMI1 in normal and leukemic human $\mathrm{CD} 34(+)$ cells impairs self-renewal and induces apoptosis. Blood 114, 1498-1505 (2009).

10. Jagani, Z. et al. The Polycomb group protein Bmi-1 is essential for the growth of multiple myeloma cells. Cancer Res. 70, 5528-5538 (2010).

11. Liu, L., Andrews, L. G. \& Tollefsbol, T. O. Loss of the human polycomb group protein BMI1 promotes cancer-specific cell death. Oncogene 25, 4370-4375 (2006).

12. Meng, X. et al. shRNA-mediated knockdown of Bmi-1 inhibit lung adenocarcinoma cell migration and metastasis. Lung Cancer 77, 24-30 (2012).

13. Ruan, Z. P. et al. Bmil knockdown inhibits hepatocarcinogenesis. Int. J. Oncol. 42, 261-268 (2013)

14. Liang, W. et al. Knockdown BMI1 expression inhibits proliferation and invasion in human bladder cancer T24 cells. Mol. Cell. Biochem. 382, 283-291 (2013).

15. Douglas, D. et al. BMI-1 promotes ewing sarcoma tumorigenicity independent of CDKN2A repression. Cancer Res. 68, 6507-6515 (2008).

16. Cao, L. et al. BMI1 as a novel target for drug discovery in cancer. J. Cell. Biochem. 112, 2729-2741 (2011).

17. Wang, M. C. et al. BMI-1, a promising therapeutic target for human cancer. Oncol. Lett. 10, 583-588 (2015). 
18. Luis, N. M., Morey, L., Di Croce, L. \& Benitah, S. A. Polycomb in stem cells: PRC1 branches out. Cell Stem Cell 11, 16-21 (2012).

19. Gil, J. \& O'Loghlen, A. PRC1 complex diversity: where is it taking us? Trends Cell Biol. 24, 632-641 (2014).

20. Vandamme, J., Volkel, P., Rosnoblet, C., Le Faou, P. \& Angrand, P. O. Interaction proteomics analysis of polycomb proteins defines distinct PRC1 complexes in mammalian cells. Mol. Cell. Proteomics 10, M110 002642 (2011).

21. Morey, L. et al. Nonoverlapping functions of the Polycomb group Cbx family of proteins in embryonic stem cells. Cell Stem Cell 10, 47-62 (2012).

22. Wang, H. et al. Role of histone $\mathrm{H} 2 \mathrm{~A}$ ubiquitination in Polycomb silencing. Nature 431, 873-878 (2004).

23. Cao, R., Tsukada, Y. \& Zhang, Y. Role of Bmi-1 and Ring1A in H2A ubiquitylation and Hox gene silencing. Mol. Cell 20, 845-854 (2005).

24. Simon, J. A. \& Kingston, R. E. Mechanisms of polycomb gene silencing: knowns and unknowns. Nat. Rev. Mol. Cell. Biol. 10, 697-708 (2009).

25. Di Croce, L. \& Helin, K. Transcriptional regulation by Polycomb group proteins. Nat. Struct. Mol. Biol. 20, 1147-1155 (2013).

26. Buchwald, G. et al. Structure and E3-ligase activity of the Ring-Ring complex of polycomb proteins Bmil and Ringlb. EMBO J. 25, 2465-2474 (2006).

27. Li, Z. et al. Structure of a Bmi-1-Ring1B polycomb group ubiquitin ligase complex. J. Biol. Chem. 281, 20643-20649 (2006).

28. Ben-Saadon, R., Zaaroor, D., Ziv, T. \& Ciechanover, A. The polycomb protein Ring1B generates self atypical mixed ubiquitin chains required for its in vitro histone H2A ligase activity. Mol. Cell 24, 701-711 (2006).

29. Alkema, M. J. et al. Identification of Bmil-interacting proteins as constituents of a multimeric mammalian polycomb complex. Genes Dev. 11, 226-240 (1997).

30. Gunster, M. J. et al. Identification and characterization of interactions between the vertebrate polycomb-group protein BMI1 and human homologs of polyhomeotic. Mol. Cell. Biol. 17, 2326-2335 (1997).

31. Chagraoui, J. et al. E4F1: a novel candidate factor for mediating BMI1 function in primitive hematopoietic cells. Genes Dev. 20, 2110-2120 (2006).

32. Negishi, M. et al. A novel zinc finger protein Zfp277 mediates transcriptional repression of the Ink4a/arf locus through polycomb repressive complex 1. PLoS ONE 5, e12373 (2010).

33. Boukarabila, H. et al. The PRC1 Polycomb group complex interacts with PLZF/RARA to mediate leukemic transformation. Genes Dev. 23, 1195-1206 (2009).

34. Sanchez-Pulido, L., Devos, D., Sung, Z. R. \& Calonje, M. RAWUL: a new ubiquitin-like domain in PRC1 ring finger proteins that unveils putative plant and worm PRC1 orthologs. BMC Genomics 9, 308 (2008).

35. Yadav, A. K. et al. Deletion analysis of BMI1 oncoprotein identifies its negative regulatory domain. Mol. Cancer 9, 158 (2010).

36. Cohen, K. J., Hanna, J. S., Prescott, J. E. \& Dang, C. V. Transformation by the Bmi-1 oncoprotein correlates with its subnuclear localization but not its transcriptional suppression activity. Mol. Cell. Biol. 16, 5527-5535 (1996).

37. Dimri, G. P. et al. The Bmi-1 oncogene induces telomerase activity and immortalizes human mammary epithelial cells. Cancer Res. 62, 4736-4745 (2002).

38. Itahana, K. et al. Control of the replicative life span of human fibroblasts by p16 and the polycomb protein Bmi-1. Mol. Cell. Biol. 23, 389-401 (2003).

39. Gray, F. L., Murai, M. J., Grembecka, J. \& Cierpicki, T. Detection of disordered regions in globular proteins using (1)(3)C-detected NMR. Protein Sci. 21, 1954-1960 (2012).

40. Isono, K. et al. SAM domain polymerization links subnuclear clustering of PRC1 to gene silencing. Dev. Cell 26, 565-577 (2013).

41. Junco, S. E. et al. Structure of the polycomb group protein PCGF1 in complex with BCOR reveals basis for binding selectivity of PCGF homologs. Structure 21, 665-671 (2013).

42. Guntert, P. Automated NMR structure calculation with CYANA. Methods Mol. Biol. 278, 353-378 (2004).

43. Tyka, M. D. et al. Alternate states of proteins revealed by detailed energy landscape mapping. J. Mol. Biol. 405, 607-618 (2011).

44. Conway, P., Tyka, M. D., DiMaio, F., Konerding, D. E. \& Baker, D. Relaxation of backbone bond geometry improves protein energy landscape modeling. Protein. Sci. 23, 47-55 (2014).

45. Howlett, G. J., Minton, A. P. \& Rivas, G. Analytical ultracentrifugation for the study of protein association and assembly. Curr. Opin. Chem. Biol. 10, 430-436 (2006).

46. Krissinel, E. \& Henrick, K. Inference of macromolecular assemblies from crystalline state. J. Mol. Biol. 372, 774-797 (2007).

47. Wei, J., Zhai, L., Xu, J. \& Wang, H. Role of Bmil in H2A ubiquitylation and Hox gene silencing. J. Biol. Chem. 281, 22537-22544 (2006).
48. Saurin, A. J. et al. The human polycomb group complex associates with pericentromeric heterochromatin to form a novel nuclear domain. J. Cell Biol. 142, 887-898 (1998)

49. Wang, R. et al. Polycomb group targeting through different binding partners of RING1B C-terminal domain. Structure 18, 966-975 (2010).

50. Shaanan, B. et al. Combining experimental information from crystal and solution studies: joint X-ray and NMR refinement. Science 257, 961-964 (1992).

51. Hoffman, D. W., Cameron, C. S., Davies, C., White, S. W. \& Ramakrishnan, V. Ribosomal protein L9: a structure determination by the combined use of X-ray crystallography and NMR spectroscopy. J. Mol. Biol. 264, 1058-1071 (1996).

52. Raves, M. L. et al. Joint refinement as a tool for thorough comparison between NMR and X-ray data and structures of HU protein. J. Biomol. NMR 21, 235-248 (2001).

53. Chao, J. A. \& Williamson, J. R. Joint X-ray and NMR refinement of the yeast L30e-mRNA complex. Structure 12, 1165-1176 (2004).

54. Kim, C. A., Gingery, M., Pilpa, R. M. \& Bowie, J. U. The SAM domain of polyhomeotic forms a helical polymer. Nat. Struct. Biol. 9, 453-457 (2002).

55. Bermel, W. et al. Complete assignment of heteronuclear protein resonances by protonless NMR spectroscopy. Angew. Chem. Int. Ed. Engl. 44, 3089-3092 (2005).

56. Delaglio, F. et al. NMRPipe: a multidimensional spectral processing system based on UNIX pipes. J. Biomol. NMR 6, 277-293 (1995).

57. Goddard, T. D. \& Kneller, D. G. SPARKY 3 (University of California, San Francisco).

58. Otwinowski, Z. \& Minor, W. Processing of X-ray Diffraction Data Collected in Oscillation Mode. Methods Enzymol. 276, 307-326 (1997).

59. Barycki, J. J. et al. Biochemical characterization and crystal structure determination of human heart short chain L-3-hydroxyacyl-CoA dehydrogenase provide insights into catalytic mechanism. Biochemistry 38, 5786-5798 (1999).

60. Emsley, P. \& Cowtan, K. Coot: model-building tools for molecular graphics. Acta Crystallogr. D Biol. Crystallogr. 60, 2126-2132 (2004).

61. Murshudov, G. N., Vagin, A. A. \& Dodson, E. J. Refinement of macromolecular structures by the maximum-likelihood method. Acta Crystallogr. D Biol. Crystallogr. 53, 240-255 (1997)

62. Shen, Y., Delaglio, F., Cornilescu, G. \& Bax, A. TALOS + : a hybrid method for predicting protein backbone torsion angles from NMR chemical shifts. J. Biomol. NMR 44, 213-223 (2009).

63. Khatib, F. et al. Algorithm discovery by protein folding game players. Proc. Natl Acad. Sci. USA 108, 18949-18953 (2011).

64. Huang, P. S. et al. RosettaRemodel: a generalized framework for flexible backbone protein design. PLoS ONE 6, e24109 (2011).

65. Demeler, B. in Modern Analytical Ultracentrifugation: Techniques and Methods (The Royal Society of Chemistry, 2005).

66. Brookes, E., Cao, W. \& Demeler, B. A two-dimensional spectrum analysis for sedimentation velocity experiments of mixtures with heterogeneity in molecular weight and shape. Eur. Biophys. J. 39, 405-414 (2010).

67. Demeler, B. \& van Holde, K. E. Sedimentation velocity analysis of highly heterogeneous systems. Anal. Biochem. 335, 279-288 (2004).

68. Brookes, E. \& Demeler, B. Genetic algorithm optimization for obtaining accurate molecular weight distributions from sedimentation velocity experiments Prog. Colloid Polym. Sci. 131, 33-70 (2006).

69. Demeler, B. \& Brookes, E. Monte Carlo analysis of sedimentation experiments. Colloid Polym. Sci. 286, 129-137 (2008).

70. Shukla, S. et al. KRAS protein stability is regulated through SMURF2: UBCH5 complex-mediated beta-TrCP1 degradation. Neoplasia 16, 115-128 (2014)

\section{Acknowledgements}

This work was funded by the National Institute of Health (NIH) grants R01 CA181185 to T.C., R01 CA160467 and R01 CA201204 to J.G. and R01 CA134604 to E.R.L.; American Cancer Society Research Scholar Grants RSG-11-082-01-DMC to T.C. and RSG-13-130-01-CDD to J.G., and Leukemia and Lymphoma Society Scholar grants (1340-17) to T.C. and (1215-14) to J.G. Authors thank Dr Rual (Department of Pathology, University of Michigan) for PHC2_B plasmid. Use of the Advanced Photon Source was supported by the US Department of Energy, Office of Science, Office of Basic Energy Sciences under contract number DE-AC02-06CH11357. Use of the LS-CAT Sector 21 was supported by the Michigan Economic Development Corporation and the Michigan Technology Tri-Corridor for the support of this research program (grant 085P1000817).

\section{Author contributions}

F.G. purified proteins, performed and analysed biochemical, NMR and X-ray crystallography experiments and determined the structure; H.J.C. performed X-ray crystallography experiments and determined the crystal structure, S.S. performed biology 
experiments; A.H. generated U2OS cells with BMI1 shRNA; B.B. purified proteins; Ł.J. and M.J. performed and analysed NMR experiments; B.D. performed analytical ultracentrifugation experiments; F.G., E.R.L., J.G. and T.C. planned the experiments and wrote the manuscript with an input from all authors.

\section{Additional information}

Supplementary Information accompanies this paper at http://www.nature.com/ naturecommunications

Competing financial interests: Drs Grembecka and Cierpicki receive research support from Kura Oncology. They are also receiving compensation as members of the scientific advisory board of Kura Oncology, and they have an equity ownership in the company. Other co-authors declare no potential conflict of interest.

Reprints and permission information is available online at http://npg.nature.com/ reprintsandpermissions/
How to cite this article: Gray, F. et al. BMI1 regulates PRC1 architecture and activity through homo- and hetero-oligomerization. Nat. Commun. 7, 13343 doi: 10.1038/ ncomms13343 (2016).

Publisher's note: Springer Nature remains neutral with regard to jurisdictional claims in published maps and institutional affiliations.

(c) (i) This work is licensed under a Creative Commons Attribution 4.0 International License. The images or other third party material in this article are included in the article's Creative Commons license, unless indicated otherwise in the credit line; if the material is not included under the Creative Commons license, users will need to obtain permission from the license holder to reproduce the material To view a copy of this license, visit http://creativecommons.org/licenses/by/4.0/

(C) The Author(s) 2016 